\title{
Collaborative Environment as a Means of Forming Success of a Future Teacher of Elementary Classes in Project Activity
}

\author{
Aigul D. Syzdykbayeva ${ }^{1, \#,{ }^{*}, \text { Aliya S. Mambetalina }}{ }^{2, \#}$, Almat S. Nuradinov ${ }^{2, \#,}$ \\ Manshuk B. Kurmanbekova ${ }^{1, \#}$ and Zauret B. Kabylbekova ${ }^{3, \#}$ \\ ${ }^{1}$ Abai Kazakh National Pedagogical University, Almaty, Republic of Kazakhstan \\ ${ }^{2}$ L.N. Gumilyov Eurasian National University, Nur-Sultan, Republic of Kazakhstan \\ ${ }^{3}$ M. Auezov South Kazakhstan State University, Shymkent, Republic of Kazakhstan
}

\begin{abstract}
Objective: The purpose of the study is to determine whether future elementary school teachers are successful in project activities and whether a properly organised collaborative environment affects the outcome of project activities.

Background: In conditions when a person is the most important value and main capital of a society, the goal and product of the educational system should be human intelligence and personality. Therefore, for domestic education today, the issue of raising the status of the teaching profession and the modernisation of teacher education has become serious. The article reveals the problem of the successful formation of a future primary school teacher in project activities through a collaborative environment. The authors define the concepts of "project activity", "the success of the future primary school teacher in project activity", "project", "collaborative environment".

Method: The methodology for organising a collaborative environment in project activities is determined. The study involved two groups; the sample was 107 pupils.

Results: A programme for diagnosing the successful formation of a future primary school teacher in project activities is presented. Criteria, indicators (motivational, cognitive, activity) and levels of success formation of the future primary school teacher in project activities (intuitive, reproductive, creative) are defined.

Conclusion: As part of the study, the authors determined that a collaborative environment is an effective means of success for a future primary school teacher in design. A collaborative environment was defined as the collaboration of a teacher and pupils in solving a problem, completing a task, or creating a product.
\end{abstract}

Keywords: Project, collaborative environment, teacher, questionnaire.

\section{INTRODUCTION}

The modern teacher is faced with the need to solve a set of important pedagogical problems. This is conditioned by the introduction of Federal state educational standards for students of different categories, the design and implementation of adapted basic general education programmes for children with disabilities, as well as the need to determine the possibilities of various educational technologies in the implementation of educational and extracurricular activities of schoolchildren [1-4].

The basic educational technology is design technology. The analysis of world experience allows stating the widespread use of the project method in the education systems of different countries [5]. This technology constitutes a special area of interpersonal interaction [6]; it creates conditions for the development of life competences of students, integration of their existing abilities and skills into the various activities of

*Address correspondence to this author at the Abai Kazakh National Pedagogical University, Almaty, Republic of Kazakhstan; Tel: +77272915768. E-mail: ad-syzdykbayeva@politechnika.pro

"These authors are equally contributed. schoolchildren [7, 8]; it provides a practical orientation of teaching children with disabilities and serves to achieve the main goal of special (correctional) education - socialisation of students with disabilities [9]. In project activities, the teacher has the opportunity to develop a high level of motivation, activity, and awareness in the assimilation of knowledge and skills, the desire to follow social norms.

In the context of the design and implementation of adapted basic general educational programmes, the project method will ensure the comprehensive development of all students, pupils, regardless of the presence of cognitive or social developmental difficulties, in situations close to life [10]. With that, the authors state the presence of a contradiction between the necessity of implementing a situational-oriented approach in the practice of work with atypical children, which is a priority in educational activities with pupils with disabilities, and the lack of guidelines for its implementation in practice; between focusing on individual creative, communicative, intellectual manifestations of schoolchildren with disabilities, stimulating the level of their all-round development, and 
the necessity of organising the joint activities aimed at achieving a common goal within the framework of a given subject. This determines the relevance of the study and the implementation of its results in the practice of the correctional boarding school.

In the study, the authors determine that a collaborative environment is an effective means of creating success in project activities. The purpose of the study is to determine whether future elementary school teachers are successful in project activities and whether a properly organised collaborative environment affects the outcome of project activities upon working with children with disabilities.

\section{MATERIALS AND METHODS}

Authors developed a programme for the socialisation of children with disabilities (from 7 to 18 years old) "Give the child joy", in total 107 people took part in the project. This project was implemented on the basis of GKOU "Special (correctional) boarding school No. 7 for children with intellectual disabilities" (Almaty, Kazakhstan) and positioned by authors as a joint project activity of all educational subjects/participants in the education of children with intellectual disabilities, namely, teachers-defectologists, regular teachers, teachers of extended education, section specialists, librarian, school psychologist, social educator, parents, representatives of public organisations. The project assumed the obligatory personal participation of children with mental retardation in creative activities. The development of the project was based on the principles of humanism, the priority of universal human values, respect and tolerant attitude towards children with disabilities (with intellectual disabilities).

The purpose of the project is to create conditions for fashioning of a tolerant attitude on the part of society towards children with disabilities (with intellectual disabilities) as a condition for their successful socialisation and their adaptation in society. Researchers point out that the ability and willingness to cooperate with participants in the educational process based on understanding, recognition, and acceptance of their individual socio-psychological features allows building project interaction based on other opinions [11]. As N.N. Malofeev points out, the humane attitude of the "normal" majority to people with special psychophysical capabilities constitutes one of the conditions for the development of special education in any country [12].
Project objectives:

- inclusion of children with disabilities (with intellectual disabilities), their parents in various types of individual and collective creative activity, expanding their range of interests, potential opportunities;

- fashioning of skills for a productive interaction between children with disabilities (with intellectual disabilities) and different adults through the organisation of joint leisure activities;

- creation of a comfortable psychological environment for children with disabilities (with intellectual disabilities) through educational activities;

- provision of the opportunity to widely use the methods and means of education, art and culture, as some of the most active for the rehabilitation of children with disabilities (with intellectual disabilities).

The developed project was implemented in stages. At the first stage of the project, which authors conditionally called organisational, the empirical information about families of children with disabilities, identification of partnership opportunities, creation of an information platform for further psychological and pedagogical work with parents, teachers, and other educational subjects was gathered; the gathered information was analysed; the directions, methods, means of working in society were selected, an implementation programme was developed. The organisational stage included the development of a regulatory framework for the project; creation of a group of teachers for the implementation of the project; creation of extended educational programmes; drawing up of an action plan; material and technical support of project activities.

The activity phase of the project covers the implementation of the socialisation programme for children with disabilities. The collective of the boarding school and teachers of extended education organised a club, extracurricular, section, etc. work according to programmes of extended education. The participation of schoolchildren in the work of creative associations presumed joint activities with normatively developing children. Considering the variability of the possibilities and interests of mentally retarded students, visits to sports sections, electives were organised, participation 
in sports competitions was welcomed (in the absence of medical contraindications).

At the main stage of the project, workshops were organised for children and parents with the involvement of specialists in art and culture; activities for recreation and all-round development of children: excursions, visits to theatres, exhibitions, cinemas, libraries; planned theatrical performances for children with disabilities (Mother's Day, New Year tree, Christmas, February 23, March 8, May 9, etc.), concerts, meetings with interesting people, etc.

The priority forms of student volunteer participation in the project the authors were implementing were: organising and conducting additional classes with children, classes on fashioning of communication skills, classes on teaching computer skills to children, group and individual classes on visual arts, dance and rhythm, individual assistance in subjects, organisation of excursions to places of social and cultural significance, organisation and conduct of theme-based games and extracurricular activities. As the student volunteers from among the future primary school teachers noted, volunteer activity allows not only to become socially active, it ensures the development of several professional competencies, contributes to fashioning of communication and interaction skills with different people.

At the analytical stage of the project, its results were summed up, the effectiveness of the activities of the entire teaching staff and each service was determined separately, the data obtained were generalised, and methodological materials for the project were designed. The main activities at this stage of the project included: development and implementation of methodological products for participants in the educational process recommendations, memos, brochures, booklets, etc.; preparation and holding of research and methodological seminar, round tables, working meetings, workshops based on an educational institution for the exchange of experience in solving issues of effective socialisation of children with disabilities; participation in multi-level educational platforms for the exchange of experience in solving issues of effective socialisation of children with disabilities; compilation and release of a catalogue of children's creative works and other printed materials: postcards, calendars, etc.; preparation and holding of a photo exhibition on the progress of the project.

\section{RESULTS}

As a result of the first stage, it was revealed that parents of children with disabilities do not consider themselves competent in matters of child care $(44.6 \%)$, treatment $(34.6 \%)$, upbringing $(63.3 \%)$, education (55.2\%), communication (77.4\%), development (44.6\%). Parents expressed dissatisfaction with the lack of subject matter experts (defectologists) in educational institutions (79.1\%). A survey of teachers working with children with disabilities in a mass school indicated that $53.2 \%$ of teachers do not see the potential development opportunities for atypical children and $26.6 \%$ of teachers never involve children with disabilities in general class activities. This has a negative impact on the effectiveness of the upbringing and education of a child with special development and its socialisation.

Future primary school teachers were widely involved in the project activities of teachers and parents. The questionnaire survey indicated the high potential of students to solve the tasks set by the project group. $51.5 \%$ of respondents are sure that volunteering can have an impact on solving problems of the target group; with that, $25.5 \%$ of students consider themselves not completely ready for this type of activity. Although authors also identified those students $(17.5 \%)$ who do not attach much importance to the influence of the volunteer activities of the future primary school teacher on the process of professional development, and therefore are not ready to take part in various projects of a specialised orientation.

The results of the project were:

- increase in the level of awareness of the immediate environment, social partners of the boarding school, about the psychological and pedagogical features and potential capabilities of children with disabilities (with intellectual disabilities), which contributes to the fashioning of tolerant consciousness and the development of empathy in relation to children with special educational needs;

- reduction of factors of socio-psychological tension in families of children with mental retardation (with intellectual disabilities);

- $\quad$ creation of conditions for creative self-fulfilment of children with disabilities (intellectual disabilities) in the process of positive social interaction; 
- the possibility of applying the results of the project in educational work with parents of children with disabilities and teachers upon giving lectures, upon conducting special workshops, psychological and pedagogical readings, workshops, in the work of laboratories in institutions of primary and secondary professional education, in the process of volunteering.

The positive results of the project activities of teachers, parents, and network partners gave the opportunity to put forward the urgent tasks of organising an effective educational process in a boarding school in the context of the implementation of new standards and adapted basic general educational programmes:

- to determine the possibility of entering the situation of practical construction of the pedagogical process through the project for each educational subject, necessarily correlating the content of the project with the real school situation, the reality of the implementation of ideas in practice;

- $\quad$ to recommend a comprehensive discussion on the organisation and results of project activities at school methodological associations, teachers' councils, scientific and practical seminars;

- $\quad$ to conduct theoretical courses for teachers who ensure mastery of design techniques.

\section{DISCUSSION}

The project method is one of the personalityoriented technologies, which is based on the development of students' cognitive skills, the ability to independently construct their knowledge, navigate the information space, and develop critical and creative thinking. This is a way to achieve an educational result through the solution of a problem. The important thing is that the result is practical, quite real, and tangible, which is exactly what children need. A project for a student with disabilities is an opportunity to do something unassisted, in a group or on their own; this is an activity that allows to prove oneself, try one's hand and publicly show the achieved result. An indispensable condition for project activities is the presence of pre-developed ideas about the final product of the activity, stages of design and implementation of the project, including reflection of the results of activities $[13,14]$.
It is with the help of project activities that the teacher tries to develop and bring children with developmental disabilities as close as possible to the norm and a safe entry into society. For a correctional teacher, this is not an easy task, since society is not always ready to accept a special child as an equal; therefore, the teacher is required to take the most thoughtful actions not only upon designing creative activity in the form of a project, but also when presenting the child in society on the paw with other normally developing, and possibly even gifted children.

A collaborative environment is an educational approach to teaching and learning, involving the collaboration of a teacher and pupils in solving a problem, completing a task, or creating a product. A collaborative environment is a unit of collaborative learning. Collaborative learning (training in cooperation) is a joint (divided, distributed) training, as a result of which pupils work together, collectively constructing, producing new knowledge, and not consuming them in a ready-made form. Collaborative learning is based on the idea that learning is social in nature, an activity in which participants communicate with each other in an atmosphere of cooperation, mutual understanding, and goodwill [15].

Collaboration is an important aspect of how this world functions today and an element that underlies the rich learning opportunities. The role of educational institutions is that they must create provocative conditions so that learning is deep and sustainable far beyond the classroom walls. Pupils are currently in a paradigm where they can study at any time of the day; they are no longer in a framework where learning is exceptional within the classroom [16]. For example, in the studies of H. Gravina, Pereira-Raso [17], teachers and pupils of Bishop Streiken's school study this issue using various teaching and learning methods and enrich these strategies using Web 2.0. Applications, social networking tools (NINGs), Interactive timelines and real-time applications (Google apps). Each of these cases provides an authentic learning experience for pupils.

Consider the importance of collaboration in project activities: it creates a friendly environment for a more free and effective solution to a problem; motivates every member of a team or group and creates a healthy environment; encourages flexibility and thus allows learners to respond faster to change; improves problem-solving by developing a combination of various solutions and abilities; supports an authorised 
way of working to eliminate any restrictions; promotes responsiveness, responsibility within a team or group; actively involves all project participants in collaboration [18]. How to create a collaborative environment in project activities [19, 20]:

1. To identify the strengths of team members. When organising collaboration, it is important to realistically assess the vulnerabilities of each member of a team or group. To start cooperation, it is necessary to create a team of pupils who complement each other. One participant compensates for the ignorance of another. It can be easily determined which team member will participate in which part of a project, comparing them with the corresponding tasks that correspond to his strengths.

2. To set realistic expectations and to clarify goals. With clear, realistic expectations in the team, pupils will be able to focus more on the tasks of a project and take part in decision making. Together, a team gets the opportunity to share their ideas and get support. To clarify the roles for each team member, it is necessary to do the following: view their roles; check responsibilities; clarify expectations; allow cross-training.

3. Tools for collaboration. It is worth actively using online collaboration software to improve cooperation; it has been shown to be effective during the quarantine period. For example, cloud collaboration technology allows accessing data from anywhere to enable pupils to work together on a common platform. Team members can exchange files at the same time, communicate in real-time and interact with each other, showing more creativity.

4. Encourage openness. A project involves various pupils. Give each of them the opportunity to be open-minded about their ideas and behaviour. Approach each situation uniquely, from a different perspective. When pupils share their experiences, this creates a sense of security in the team. They give a respectful approach to work, which positively affects the overall performance.

5. Remuneration for innovation. For a collaborative environment and its effective functioning, a system of rewards is needed for the manifestation of innovative thinking when solving a problem. This will increase competitiveness between teams (group members) that are involved in a project.

6. To publicly celebrate the success of the team. It is important not to forget to celebrate the success of a team to improve team spirit and performance; for example, it would be great to encourage them with approval (possibly even material). It is worth motivating them to share their success story to make a difference. This is more likely to increase their confidence and make them more inspired to contribute more to a team. It is necessary to show them that their efforts are not taken for granted [21, 22].

7. To maintain a strong sense of community. It is very important to share a sense of community where everyone feels comfortable. No one wants to be part of a team in which they feel like a stranger. This destroys the whole meaning of teamwork and makes it impossible to achieve anything meaningful. A team should feel a strong sense of community, feel more comfortable, correctly share the necessary knowledge and help solve deep problems and not only within a project $[23,24]$.

8. The distribution of tasks within a team. The distribution of tasks within a team depends on the abilities of pupils, but it is impossible for the same pupils to be delegated when carrying out project activities. Everyone must be motivated to be in a team and make their efforts in solving the task. For a collaborative environment to flourish, do not let anyone get hurt by a team or group performing a project.

\section{CONCLUSIONS}

In the context of design and implementation of adapted basic general educational programmes, it is the project method that will ensure the comprehensive development of all students, pupils, regardless of the presence of cognitive or social developmental difficulties, in situations close to life. Thus, a situationaloriented approach will be implemented, which is a priority in upbringing and educational activities with pupils with intellectual disabilities. In this case, focusing on the needs, interests, desires, and problems of children, their long-term joint activities will be directed by the teacher to achieve a certain goal within a given topic, during the implementation of which creative, 
communicative, intellectual manifestations are stimulated in children, stimulating the level of their allround development. Such an approach, with its skilful and well-thought-out organisation, obviously has an impact on the development of both the entire group of pupils and each individual child.

Education ceases to be a learning activity that takes place in educational institutions, in specially organised conditions and becomes a life process that takes place throughout the active life of an individual. Education, in this sense, is a person's projection of his life activity; the sphere of education is an area of social life in which the conditions necessary for such a design are created. Projective education acts as a form of continuing education of an individual. It is called projective not because it uses a project as a teaching method, but because it, itself is a means of creating and implementing any projects and technologies that have a vital, and not just educational, meaning for a pupil.

The study does not claim to be an exhaustive solution to the problem of ensuring success in project activities among future primary school teachers of children with disabilities and represents only one of the options for approaching its solution. The accumulated theoretical and practical material requires elaboration and clarification for further development and improvement of the subject matter within the framework of extended education.

\section{ACKNOWLEDGEMENT}

The authors are grateful to the Abai Kazakh National Pedagogical University and the Kazakh National Women's Pedagogical University for the possibility of organising experimental work and testing the results of the study. The article was published at the expense of grant funding "The best teacher of the university 2019".

\section{REFERENCES}

[1] The Law of the Republic of Kazakhstan "On the status of the teacher" 2019. Available at: http://adilet.zan.kz/rus/docs/ Z1900000293.

[2] The state programme for the development of education and science of the Republic of Kazakhstan for 2020-2025 2019. Available at: http://adilet.zan.kz/rus/docs/P1900000988.

[3] Burkov VN, Novikov DA. How to manage projects. Moscow: NPO SINTEG, ICP Geo, 1997.

[4] Novikov AM, Novikov DA. Educational project (educational activity methodology). Moscow: Egves, 2004.
[5] Kolesnikova IA, Gorchakova-Sibirskaya MP. Pedagogical design: Textbook. Allowance for higher Institutions. Moscow: Publishing Center "Academy" 2005.

[6] Safontseva NYu. Designing pedagogical objects in the conditions of continuing professional education on the basis of the cluster method. Rostov-on-Don: South Federal University, 2007.

[7] Chen C, Yang Y. Revisiting the effects of project-based learning on pupils' academic achievement: A meta-analysis investigating moderators. Educational Research Review 2019; 26: 71-81. https://doi.org/10.1016/j.edurev.2018.11.001

[8] Avouris N, Komis V, Margaritis M, Fiotakis G. An environment for studying collaborative learning activities. Journal of Educational Technology \& Society 2004; 7(2): 3441.

[9] Syzdykbaeva AD. Formation of the research competence of a future primary school teacher. Almaty: Kazakh National Pedagogical University named after Abay 2016.

[10] Scager K, Boonstra J, Peeters T, Vulperhorst J, Wiegant F. Collaborative learning in higher education: Evoking positive interdependence. CBE: Life Sciences Education 2016; 15(4): article number ar69. https://doi.org/10.1187/cbe.16-07-0219

[11] Mann-Whitney U-test. Available at: https://www.psycholok.ru/statistics/mann-whitney/.

[12] The educational programme of the specialty 5B010200 Pedagogy and methodology of elementary education KazNPU named after Abay 2018a. Available at: http://kaznpu.kz/ru/744/page/.

[13] The educational programme of the specialty 5B010200 Pedagogy and methods of elementary education KazGosZhenPU 2018b. Available at: https://iqaa.kz/images/ otchety/Specialized_Accreditation/2018/rus.

[14] T-Wilcoxon test 2019. Available at: https://www.psycholok.ru/statistics/wilcoxon/.

[15] Dillenbourg P. (Ed.). What do you mean by collaborative learning? Collaborative Learning: Cognitive and Computational Approaches. Advances in Learning and Instruction Series. Oxford: Elsevier, 1999.

[16] Bekturova ZK. The formation of a collaborative learning environment as a factor in the implementation of updated programmes. International Journal of Experimental Education 201; 11(2): 271-272.

[17] Gravina RH. Technology: A Tool for Creating Collaborative Learning Environments 2013 https://doi.org/10.4018/978-1-4666-1936-4.ch007

[18] Swink M. Building a collaborative innovation capability. Research Technology Management 2006; 49(2): 37-47. https://doi.org/10.1080/08956308.2006.11657367

[19] Marjanovic O. Learning and teaching in a synchronous collaborative environment. Journal Learning, 2002, 15(2), 129-38.

https://doi.org/10.1046/j.1365-2729.1999.152085.x

[20] Mandrikova GM. Training in cooperation: pupil's point of view. Novosibirsk: NSTU, 2010.

[21] Sun J, Chen A, Yeh K, Cheng Y, Lin Y. Is Group Polling Better? An Investigation of the Effect of Individual and Group Polling Strategies on Pupils' Academic Performance, Anxiety, and Attention. Journal of Educational Technology \& Society 2018; 21(1): 12-24.

[22] Syzdykbayeva AD, Bainazarova TB, Aitzhanova EN Formation of research competence of the future elementary school teachers - in the process of professional training. International Education Studies 2015; 8(4): 200-209. https://doi.org/10.5539/ies.v8n4p200 
[23] Khan N, Kolumbayeva Sh, Karsybayeva R, Nabuova R, Syzdykbayeva A. Evaluation of the Program Effectiveness of Research Competence Development in Prospective Elementary School Teachers. International Journal of Environmental and Science Education (IJESE) 2016; 11(18): 12299-12316.
[24] Khan N, Syzdykbayeva A, Kinzhibaeva F, Demesheva G, Abilova O. Organization of teaching practice of future primary school teachers in the context of dual training system: Kazakhstan experience. International Journal of Educational Management 2018; 32(5): 942-954.

https://doi.org/10.1108/IJEM-07-2017-0183

Received on 05-08-2020

Accepted on 02-09-2020

Published on 14-09-2020

DOI: https://doi.org/10.6000/2292-2598.2020.08.03.13

(C) 2020 Syzdykbayeva et al.; Licensee Lifescience Global.

This is an open access article licensed under the terms of the Creative Commons Attribution Non-Commercial License (http://creativecommons.org/licenses/by-nc/3.0/) which permits unrestricted, non-commercial use, distribution and reproduction in any medium, provided the work is properly cited. 